\title{
Diversification, common ownership, and strategic incentives
}

\author{
By Albert Banal-Estanol, Jo Seldeslachts and Xavier Vives*
}

We investigate how changes in firms' ownership structures affect their strategic incentives in product markets. We show that firms' common ownership incentives, i.e., the profit loads managers should place on competing firms, increase if the holdings of more diversified investors' increase relative to those of less diversified investors.

We distinguish between two type of investors, active versus passive investors. Active fund managers choose individual investments in order to try to beat the market, whereas passive fund managers replicate existing stock indices by buying shares of all the member firms of this particular index. Because of their investment strategy, passive investors are more diversified than active investors. Thus, if passive investors become relatively more important than active investors over time, within-industry investor diversification increases and, as we argue, common ownership incentives increase as well.

In Banal-Estanol, Seldeslachts and Vives (2020), BSV for short, we show empirically that the vast majority of U.S. industries has indeed seen a massive increase in money flows from active towards passive investors from 2004 to 2012. We also confirm that passive investors are on average more di-

\footnotetext{
* Banal-Estanol: Universitat Pompeu Fabra and City University London, Ramon Trias Fargas, 23-25, 08005 Barcelona, Spain, albert.banalestanol@upf.edu. Seldeslachts: KU Leuven and DIW Berlin, Naamsestraat 69, 300 Leuven, Belgium, jo.seldeslachts@kuleuven.be. Vives: IESE Business School, Av. Pearson 21, 08034, Barcelona, Spain, xvives @iese.edu. We benefited from participant's comments at the ASSA meeting, seminars at DIW Berlin and IESE, and from Nuria Boot. We like to thank Anna Sama, and especially Dmitry Khametshin and Andre Sousa for their outstanding research assistance. Banal-Estanol acknowledges financial support from the Spanish Ministry of Economy and Competitiveness (ECO2016-76998-P) and the Severo Ochoa Program (SEV-2015-0563). Vives acknowledges financial support from the European Research Council (Advanced Grant No 789013).
}

versified than active investors across U.S. industries. We use both pieces of evidence to explain the general rise in common ownership incentives in recent times.

We illustrate in this paper, through two industry examples, that within-industry investor diversification is directly related to common ownership incentives. In our two example industries, department stores and publishers, as in virtually all industries, passive investors are more diversified than active investors but, contrary to the main pattern, passive investors' relative holdings have been fluctuating over the sample period. We show graphically that, in these two industries when the holdings of the passive investors increase, then common ownership incentives increase. On the contrary when the holdings of the active investors increase, then common ownership incentives decrease.

Azar and Vives (2019 a, b) and Backus, Conlon and Sinkinson (2018) compute common ownership profit loads for U.S. publicly traded firms and document their rise in the last decades. This last work also associates the rise of those profits loads to the increase in margins observed in empirical studies (e.g., De Loecker, Eeckhout and Unger, forth.) using Cournot or Bertrand competition specifications. ${ }^{1}$ Earlier work associating increasing common ownership with a softening of competition focused on the modified Herfindal-Hirschman Index (MHHI). ${ }^{2}$ However, the use of the MHHI index has been controversial since it depends on market shares of firms within an indus-

\footnotetext{
${ }^{1}$ Using a different measure of competition, Newham, Seldeslachts and Banal-Estanol (2018) link higher common ownership incentives to reduced entry in pharmaceutical markets.

${ }^{2}$ Azar, Schmalz and Tecu (2018) kicked off the empirical literature on the topic by assessing the price effects of common ownership in airlines, whereas Gutierrez and Philippon (2017) employ measures of MHHI to study the impact of common ownership on investment.
} 
try -hence endogenous by nature.

\section{Definitions}

We now define the variables we use in both the theoretical and empirical analyses. We define the market $S$ average degree of portfolio diversification of a group of investors of type $\tau=A, P$ (active and passive, respectively) ${ }^{3}$

$$
D I V_{S}^{\tau} \equiv \frac{1}{|\tau|} \sum_{i \in \tau}\left[1-\sum_{j \in S}\left(\frac{h_{i j}}{\sum_{k \in S} h_{i k}}\right)^{2}\right],
$$

with $h_{i k}$ being the holdings of investor $i$ in firm $k$ and $|\tau|$ the number of investors of type $\tau$. Within-industry investor diversification is defined, following standard practice, as one minus the concentration (HHI) of investor's holdings across firms.

We define the average level of relative holdings of passive investors as

$$
R L H_{S}^{P} \equiv \frac{1}{|S|} \sum_{j \in S} \frac{\sum_{i \in P} h_{i j}}{\sum_{i \in A \cup P} h_{i j}},
$$

with $|S|$ being the number of firms in industry $S$.

We now define the average common ownership incentives in industry $S$ (assuming proportional control). The common ownership incentives of each firm $j$ are equal to the weights ("lambdas") that the manager of this firm should place on each of the other firms $k$ in the market, relative to the weight firm $j$ places to its own profits, in its objective function. The weights correspond to Edgeworth's coefficients of "effective sympathy" between firms (Lopez and Vives, 2019):

$$
\lambda_{S} \equiv \frac{1}{|S|(|S|-1)} \sum_{j, k \in S} \frac{\sum_{i \in A \cup P} \beta_{i j} \beta_{i k}}{\sum_{i \in A \cup P} \beta_{i j}^{2}}
$$

with $\beta_{i j}=h_{i j} / \sum_{l} h_{l j}$ being the investor $i$ 's ownership stake in firm $j$.

\footnotetext{
${ }^{3} \tau, A$, and $P$ denote sets. We use $|\cdot|$ to denote the number of elements in a set.
}

\section{Theoretical framework}

To show the effects of within-industry diversification on common ownership incentives, we take a particular (extreme) case of the model developed in BSV. We consider a parametrization of the ownership structure of an industry, which allows passive and active investors to differ in terms of holdings and diversification, while retaining symmetry in terms of firm ownership and valuation for within-type investors.

Suppose that each of the $n$ symmetric firms in the industry has one fullyundiversified active investor and $n$ fullydiversified passive investors. Each of the active investors invest the same amount in only one firm whereas each of the passive investors invest the same amount in all firms in the industry. The active and passive investors may own different fractions of the firms. We denote the fraction of the shares owned by the active investors by $1-\sigma$ whereas the active investors are assumed to own, in total, $\sigma$ of the shares of the firm $(\sigma \in[0,1])$. Formally, each active investor $i$ owns a fraction $\beta_{i j}=1-\sigma$ of firm $j=i$ and a fraction $\beta_{i j}=0$ of any other firm $j \neq i$, whereas each passive investor $i$ owns a fraction $\beta_{i j}=\sigma / n$ of each firm $j$.

We now substitute the holdings of this ownership structure into the variables defined in the previous section. Substituting the $\beta_{i j}$ 's into $D I V_{S}^{\tau}$ :

$$
D I V_{S}^{P}=(n-1) / n>0=D I V_{S}^{A},
$$

whereas substituting the $\beta_{i j}$ 's into $R L H_{S}^{P}$ :

$$
R L H_{S}^{P}=\sigma,
$$

and finally, substituting the $\beta_{i j}$ 's into $\lambda_{S}$ :

$$
\lambda_{S}=\frac{1}{1+n \frac{(1-\sigma)^{2}}{\sigma^{2}}} .
$$

These expressions show that, as the holdings of the passive investors $R L H_{S}^{P}$, parametrized by $\sigma$, increase, relative to those of the active investors (with $D I V_{S}^{P}>$ $\left.D I V_{S}^{A}\right)$, the common ownership incentives of the industry $\lambda_{S}$ increase. This result can 
be generalized to intermediate levels of diversification, different levels of concentration of each type of investors, as well as different levels of control (see BSV).

\section{Data and illustration}

We make use of the Thomson Reuters Global One Ownership Database for the period 2004-2012, which includes ownership data of publicly-listed US firms as well as information about the orientation of the investors. $^{4}$

Thomson Reuters classifies investors into two categories, depending on how they manage their portfolios. Broadly speaking, "active" investors are considered to be those that manage their portfolio using a hands-on approach to determine their investments whereas "passive" investors are expected to be those that benchmark their assets against stock market indices and allow external factors to determine in which firms they invest in. We make use of this classification into two categories to create two groups of investors, with different levels of within-industry diversification, and analyze how the changes in the ownership holdings of each group affect the firms' common ownership incentives.

For firms' presence and sales in US industries, we use the WRDS Compustat North America data files that record accountancy data for US publicly listed firms. We, thus, obtain all publicly traded firms over the period 2004-2012, provided by Compustat (excluding finance). Because there is no official filing requirement for the privately held firms, our data does not include any privately held firms.

We take two example industries: "Department stores" (NAICS 4521) and "Newspaper, Periodical, Book, and Di-

\footnotetext{
${ }^{4}$ This database utilizes a "money-manager view." Our database attempts to assign the decision maker, which is often not the same as the filer; see also Backus et al. (2019). We therefore supplement the data obtained from Thomson with data from the National Information Center (NIC). Furthermore, to fully account for changes in investor name that occurred through the sample as a result of mergers, acquisitions and partial sales, we modified the data provided by Thomson Reuters.
}

rectory Publishers" (NAICS 5111). In both industries, as shown by the upper panels in Figures 1 and 2, the passive investors are on average more diversified than the active investors in each of the years of the sample $\left(D I V^{P}>D I V^{A}\right)$. In terms of holdings, though, as shown by the middle panels in Figures 1 and 2, the passive/active ownership split of shares, $R L H^{P}$, fluctuates.

\section{[Insert Figure 1 about here] [Insert Figure 2 about here]}

As shown by the lower panels in Figures 1 and 2, the common ownership incentives, $\lambda$, co-move with the relative holdings of passive investors.

The results obtained in these two industries generalize to a broad spectrum of US industries, where the vast majority of industries shows a pattern of increased money holdings for passive investors. Changes in money flows and resulting common ownership incentives can then be empirically linked to changes in markups, as we show in BSV.

\section{REFERENCES}

Azar, José, Martin C. Schmalz, and Isabel Tecu. 2018. "Anticompetitive Effects of Common Ownership." The Journal of Finance 73(4): 1513-1565.

Azar, José, and Xavier Vives. 2019. "Common Ownership and the Secular Stagnation Hypothesis." AEA PEPS 109: 32226.

Azar, José, and Xavier Vives. 2019. "General Equilibrium Oligopoly and Ownership Structure." Available at SSRN 3501611.

Backus, Matthew, Christopher Conlon, and Michael Sinkinson. 2019. "Common Ownership in America: 19802017." No. w25454. NBER.

Banal-Estanol, Albert, Jo Seldeslachts, and Xavier Vives. 2020. "Financial Markets, Common Ownership and Product Market Outcomes." Mimeo. 
De Loecker, Jan, Jan Eeckhout, and Gabriel Unger. Forthcoming. "The Rise of Market Power and the Macroeconomic Implications." The Quarterly Journal of Economics.

Gutierrez, Germán, and Thomas Philippon. 2017. "Declining Competition and Investment in the US." No. w23583. National Bureau of Economic Research.

Lopez, Angel, and Xavier Vives. 2019. "Overlapping Ownership, R\&D Spillovers, and Antitrust Policy." Journal of Political Economy, 127(5): 2394-2437.

Newham, Melissa, Jo Seldeslachts, and Albert Banal-Estanol. 2018. "Common Ownership and Market Entry: Evidence from Pharmaceutical Industry." No. 1738. DIW Berlin, German Institute for Economic Research.
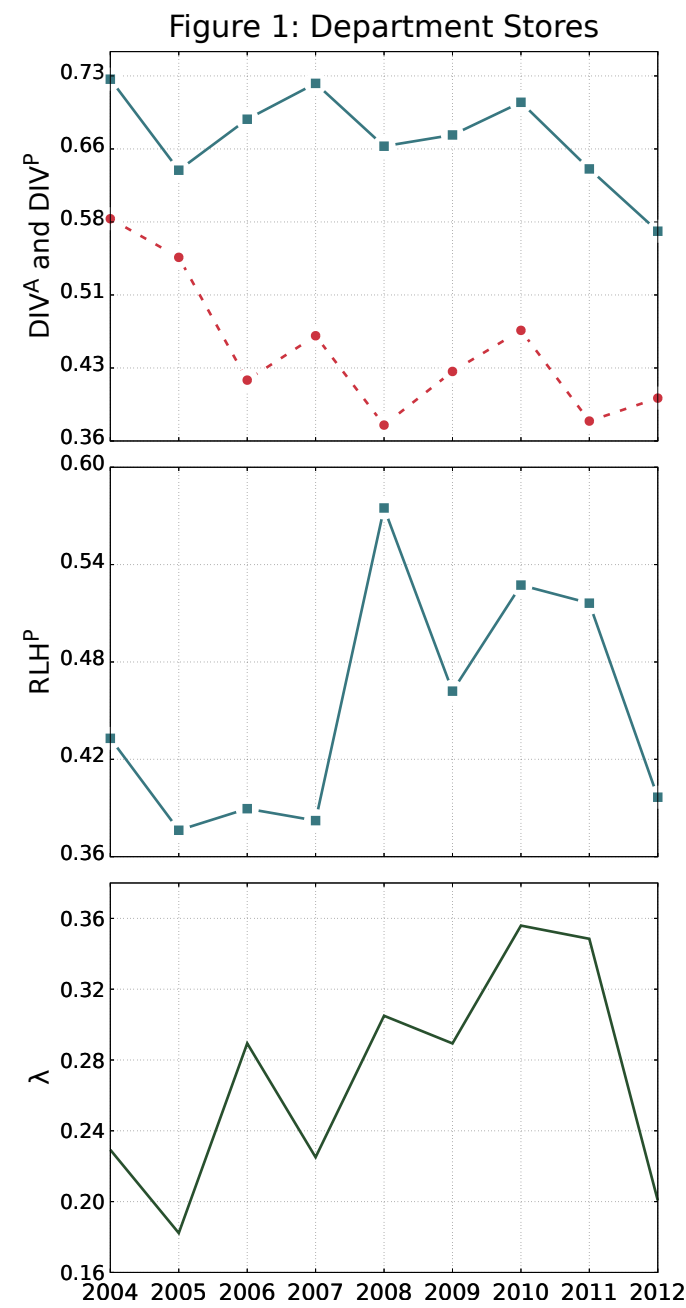

Note: Blue solid lines with squares represent passive investors, red dotted lines represent active investors, and black solid lines represent all investors.
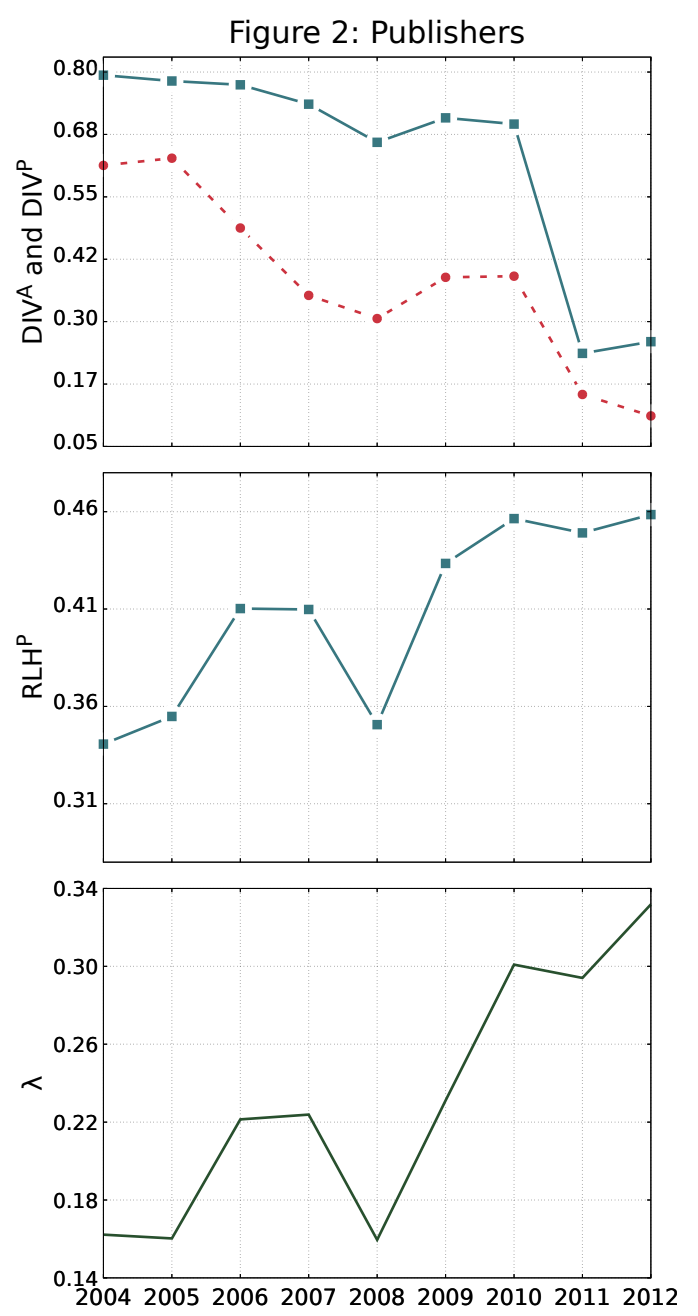

Note: Blue solid lines with squares represent passive investors, red dotted lines represent active investors, and black solid lines represent all investors. 